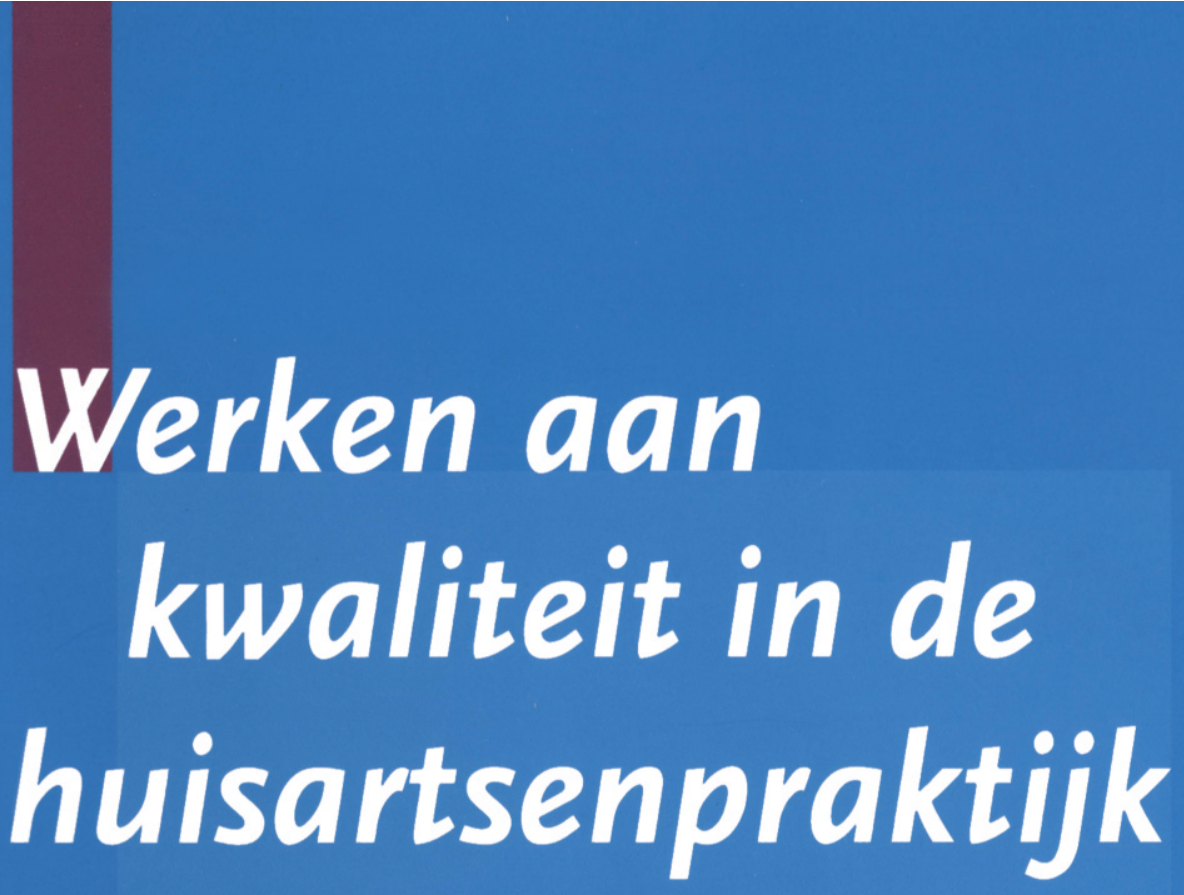

Indicatoren gebaseerd op de NHG-Standaarden

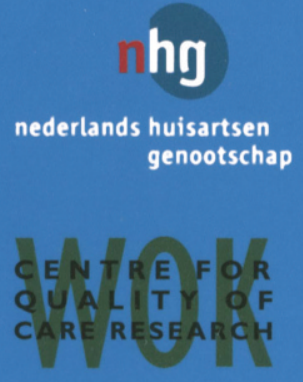

onder redactie van

J.C.C. Braspenning

L. Pijnenborg

C.J. in 't Veld

R.P.T.M. Grol

Bohn Stafleu van Loghum 
WERKEN AAN KWALITEIT IN DE HUISARTSENPRAKTIJK 



\section{WERKEN AAN KWALITEIT \\ IN DE HUISARTSENPRAKTIJK}

\section{INDICATOREN GEBASEERD OP DE NHG-STANDAARDEN}

Onder redactie van:

Dr. J.C.C. Braspenning

Dr. L. Pijnenborg

Drs. C.J. in 't Veld

Prof. dr. R.P.T.M. Grol

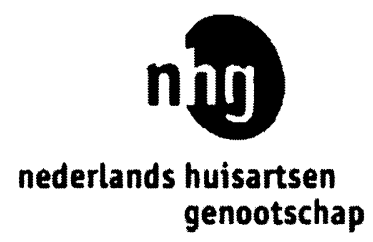

CENTRE FOR QUALITY O F CARE RESEARCH 
(C) 2005 Bohn Stafleu van Loghum, Houten

Alle rechten voorbehouden. Niets uit deze uitgave mag worden verveelvoudigd, opgeslagen in een geautomatiseerd gegevensbestand of openbaar gemaakt, in enige vorm of op enige wijze, hetzij elektronisch, mechanisch, door fotokopieën, opnamen, of op enige andere manier, zonder voorafgaande schriftelijke toestemming van de uitgever.

Voorzover het maken van kopieën uit deze uitgave is toegestaan op grond van artikel $16 \mathrm{~b}$ Auteurswet I9I2 $j^{\circ}$ het Besluit van 20 juni I974, Stb. 35I, zoals gewijzigd bij Besluit van 23 augustus 1985, Stb. 47I en artikel I7 Auteurswet I9I2, dient men de daarvoor wettelijk verschuldigde vergoedingen te voldoen aan de Stichting Reprorecht (Postbus 3060, 2130 KB Hoofddorp). Voor het overnemen van (een) gedeelte(n) uit deze uitgave in bloemlezingen, readers en andere compilatiewerken (artikel I6 Auteurswet I9I2) dient men zich tot de uitgever te wenden.

ISBN 903134624 I

NUR 87 I

Ontwerp omslag en binnenwerk: Peter Walvius bNo, Nijmegen

Eerste druk, 2005

Bohn Stafleu van Loghum

Het Spoor 2

Postbus 246

3990 GA Houten

www.bsl.nl

Distributeur in België:

Belgiëlei I47a

2018 Antwerpen

www.standaarduitgeverij.be 


\section{AUTEURS}

M.J.P. VAN AVENDONK

Huisarts, junior-onderzoeker afdeling Kwaliteit van zorg (woK), Universitair Medisch Centrum St. Radboud, Nijmegen

\section{J.A.M. VAN BALEN}

Huisarts, wetenschappelijk medewerker afdeling Richtlijnontwikkeling, Nederlands Huisartsen Genootschap, Utrecht

\section{L.J. BOOMSMA}

Huisarts, wetenschappelijk medewerker afdeling Richtlijnontwikkeling, Nederlands Huisartsen Genootschap, Utrecht

\section{F.S. BOUKES}

Huisarts, wetenschappelijk medewerker afdeling Richtlijnontwikkeling, Nederlands Huisartsen Genootschap, Utrecht

\section{DR. M. BOUMA}

Huisarts, wetenschappelijk medewerker afdeling Richtlijnontwikkeling, Nederlands Huisartsen Genootschap, Utrecht

DR. J.C.C. BRASPENNING

Senior-onderzoeker afdeling Kwaliteit van zorg (wok), Universitair Medisch Centrum St. Radboud, Nijmegen

DR. R.F. DIJKSTRA

Huisarts, senior-onderzoeker afdeling Kwaliteit van zorg (woK), Universitair Medisch Centrum St. Radboud, Nijmegen

W.H. EIZENGA

Huisarts, wetenschappelijk medewerker afdeling Richtlijnontwikkeling, Nederlands Huisartsen Genootschap, Utrecht

DR. A.N. GOUDSWAARD

Huisarts, hoofd afdeling Richtlijnontwikkeling, Nederlands Huisartsen Genootschap, Utrecht 
PROF. DR R.P.T.M. GROL

Hoogleraar Kwaliteit van zorg afdeling Kwaliteit van zorg (woK), Universitair Medisch Centrum St. Radboud, Nijmegen

DR. B.G.M. KOLNAAR

Huisarts, wetenschappelijk medewerker afdeling Richtlijnontwikkeling, Nederlands Huisartsen Genootschap, Utrecht

\section{M.G.H. LAURANT}

Senior-onderzoeker afdeling Kwaliteit van zorg (woK), Universitair Medisch Centrum St. Radboud, Nijmegen

J. VAN LIESHOUT

Huisarts, wetenschappelijk medewerker afdeling Richtlijnontwikkeling, Nederlands Huisartsen Genootschap, Utrecht

N.G.C.B. VAN LIN

Junior-onderzoeker afdeling Kwaliteit van zorg (woK), Universitair Medisch Centrum St. Radboud, Nijmegen

DR. J.W.M. MURIS

Huisarts, onderzoeker Huisartsgeneeskunde (wok), Universiteit Maastricht

DR. L. PIJNENBORG

Huisarts, senior wetenschappelijk medewerker afdeling Richtlijnontwikkeling, Nederlands Huisartsen Genootschap, Utrecht

B. VAN PINXTEREN

Huisarts, wetenschappelijk medewerker afdeling Richtlijnontwikkeling, Nederlands Huisartsen Genootschap, Utrecht

A.C.M. ROMEIJNDERS

Huisarts, wetenschappelijk medewerker afdeling Richtlijnontwikkeling, Nederlands Huisartsen Genootschap, Utrecht

DR. M.S. VAN ROOSMALEN

Epidemioloog, afdeling Kwaliteit van zorg (wok), Universitair Medisch Centrum St. Radboud, Nijmegen

DR. H.J. SCHERS

Huisarts, onderzoeker afdeling Huisartsgeneeskunde (HAG), Universitair Medisch Centrum St. Radboud, Nijmegen 
Junior-onderzoeker afdeling Kwaliteit van zorg (wok), Universitair Medisch Centrum St. Radboud, Nijmegen

T.H. SPIES

Huisarts, onderzoeker afdeling Kwaliteit van zorg (wok), Universitair Medisch Centrum St. Radboud, Nijmegen

\section{J.S. STARREVELD}

Huisarts, wetenschappelijk medewerker afdeling Richtlijnontwikkeling, Nederlands Huisartsen Genootschap, Utrecht

M.A.J.B. TACKEN

Junior-onderzoeker afdeling Kwaliteit van zorg (woK), Universitair Medisch Centrum St. Radboud, Nijmegen

DR. B.P.A. THOONEN

Huisarts, afdeling Huisartsenopleiding ( Centrum St. Radboud, Nijmegen

C.J. IN 'T VELD

Huisarts, hoofd afdeling Implementatie, Nederlands Huisartsen Genootschap, Utrecht

\section{G.M. VAN DER WEELE}

Huisarts, wetenschappelijk medewerker afdeling Richtlijnontwikkeling, Nederlands Huisartsen Genootschap, Utrecht

H. WITMER

Huisarts, senior wetenschappelijk medewerker afdeling Implementatie, Nederlands Huisartsen Genootschap, Utrecht

R.J. WOLTERS

Huisarts, junior-onderzoeker afdeling Kwaliteit van zorg (wok), Universitair Medisch Centrum St. Radboud, Nijmegen 

Het Nederlands Huisartsen Genootschap (NHG) wil de wetenschappelijk onderbouwde uitoefening van de huisartsgeneeskunde in de praktijk bevorderen en ondersteunen. Het NHG trekt hierbij samen op met het 'Centre for Quality of Care Research' (wok).

Richtlijnen maken - onontbeerlijk voor de inhoudelijke ontwikkeling van het vak - gaat hand in hand met allerlei strategieën om huisartsen en waar nodig anderen die werkzaam zijn in een huisartsenpraktijk, te ondersteunen om volgens die richtlijnen te werken. Voor dit kwaliteitsbeleid is het tevens belangrijk om het effect te kunnen meten en om dat zorgvuldig te doen zijn goede indicatoren nodig.

Dat laatste is gemakkelijker gezegd dan gedaan. Het meten de kwaliteit van de geleverde zorg kan bijvoorbeeld verschillende, zowel in- als externe, doelen dienen. Indicatoren kunnen bijvoorbeeld gebruikt worden voor interne kwaliteitsverbetering in de praktijk of van de beroepsgroep van huisartsen. Daarnaast kunnen indicatoren gebruikt worden voor de externe verantwoording die van de huisartsgeneeskunde gevraagd wordt van aard, kwaliteit en kwantiteit van geleverde zorg. Het blijkt in praktijk niet altijd eenvoudig grip te krijgen op de geldigheid en reikwijdte van de benodigde indicatoren en die op passende wijze te valideren. Temeer daar de bruikbaarheid van indicatoren alleen tot haar recht komt als óók recht is gedaan aan de specifieke context waarin huisartsgeneeskundige zorg geboden wordt.

Al deze hindernissen hebben het NHG en de woк er niet van weerhouden een traditie op te bouwen van samenwerking, wetenschappelijk onderzoek en gezamenlijke activiteiten op het gebied van de bevordering van het kwaliteitsbeleid. Dit heeft onder andere geleid tot instrumenten als het Visitatie Instrument Praktijkvoering (vIP) en recentelijk het Visitatie Instrument Accreditering (VIA). Het viA wordt toegepast bij de NHG-Praktijkaccreditering ${ }^{\circledR}$. De vraag naar valide en toepasbare indicatoren is door deze ontwikkeling erg actueel. Hoewel er nog allerlei vragen op beantwoording wachten, en zich natuurlijk steeds nieuwe inzichten voordoen is goede vooruitgang bij de indicatorenontwikkeling geboekt. In dit boek kunt $u$ zich op de hoogte stellen van de huidige stand van zaken en van de indicatorenontwikkeling op het gebied van het medisch handelen. NHG-richtlijnen vormden het uitgangspunt voor de indicatoren. 
Dit boek is bedoeld voor huisartsen en huisartsenpraktijken die gedegen onderbouwd kwaliteitsbeleid-op-maat willen uitvoeren dat goed aansluit bij de specifieke eigenschappen van de eigen praktijk. Het boek sluit daarnaast goed aan bij de NHG-Praktijkaccreditering ${ }^{\circledR}$ die in 2005 geïntroduceerd is. Op termijn zou het NHG verder willen gaan op de ingeslagen weg om alle NHG-richtlijnen van een set indicatoren te voorzien. Dit boek is een belangrijke stap in die richting.

Kees in 't Veld, huisarts

Hoofd NHG-Afdeling Implementatie

Richard Grol, hoogleraar Kwaliteit van zorg

Centre for Quality of Care Research (wok) 


\section{INHOUD}

\section{Auteurs v}

\section{Voorwoord IX}

I Evalueren van de kwaliteit van zorg in de huisartsenpraktijk I R.P.T.M. Grol, J.C.C. Braspenning, C.J. in 't Veld

Kernboodschappen I

I.I Het belang van systematische kwaliteitsverbetering 2

I.2 Evaluatie van kwaliteit van zorg 3

I.3 Indicatoren 4

I.4 Welke aspecten van de huisartsenzorg lenen zich voor evaluatie? 6

I.5 Hoe kunnen gegevens over de zorg worden verzameld? 7

I.6 Meten en verbeteren 8

I.7 Doel en inhoud van dit boek 8

Referenties 9

2 Ontwikkelen van kwaliteitsindicatoren Io

J.C.C. Braspenning, L.Pijnenborg, R.P.T.M. Grol

Kernboodschappen Io

2.I Basisset van indicatoren II

2.2 Tweede Nationale Studie I3

2.3 Huidige selectie van indicatoren I4

Referenties I5

Appendix: De 6I NHG-Standaarden, waaruit I39 indicatoren

zijn gemaakt 20

3 Toepassen van kwaliteitsindicatoren $2 \mathrm{I}$

L. Pijnenborg, M. Bouma, J.C.C. Braspenning, H. Witmer

Kernboodschappen 2I

3.I De keuze van onderwerpen 2I

3.2 Meten 23

3.3 Toetsen 24

3.4 Verbeteren 28

3.5 Evalueren 28

3.6 Beperkingen en mogelijkheden 29

Referenties 29 
4 Diabetes mellitus $3 \mathrm{I}$

R.F. Dijkstra, M.J.P. van Avendonk, M. Bouma

4.I Prevalentie 3I

4.2 Controle 32

4.3 Uitkomsten 35

Referenties 37

5 Risicomanagement hart- en vaatziekten 38

M.S. van Roosmalen, M. Bouma

5.I Prevalentie hoogrisicopatiënten 38

5.2 Cardiovasculair risicoprofiel 40

5.3 Niet-medicamenteuze behandeling $4 \mathrm{I}$

5.4 Medicamenteuze behandeling 4I

5.5 Uitkomsten 44

5.6 Nieuwe ontwikkelingen $\quad 46$

Referenties 46

6 Hartfalen 48

M.S. van Roosmalen, J. van Lieshout

6.I Prevalentie 48

6.2 Diagnostiek 49

6.3 Medicamenteuze behandeling 49

6.4 Controle 50

Referenties 50

7 Astma en COPD 5I

B.P.A. Thoonen, B.G.M. Kolnaar

7.I Astma bij kinderen 5I

7.2 Astma en Copd bij volwassenen: diagnostiek 55

7.3 Astma bij volwassenen: behandeling 57

7.4 COPD: behandeling 59

Referenties 6I

8 Preventieve taken: influenzavaccinatie en bevolkingsonderzoek baarmoederhalskanker 62

M.A.J.B. Tacken, L.J. Boomsma

8.I Influenzavaccinatie 62

8.2 Het bevolkingsonderzoek naar baarmoederhalskanker $6_{5}$

Referenties 67

9 Het gericht voorschrijven van antibiotica 69 J.C.C. Braspenning, A.M. Schiere, J.A.M. van Balen

9.I Otitis media acuta 69

9.2 Acute keelpijn 70 
9.3 Kinderen met koorts 7I

9.4 Sinusitis 72

9.5 Bacteriële huidinfecties 73

9.6 Urineweginfectie 74

9.7 Acuut hoesten 76

9.8 Samenhangend antibioticabeleid 77

Referenties 78

Io Diagnostiek en behandeling van maagklachten 80
B. van Pinxteren, J.W.M. Muris

IO.I Diagnostiek 8I

I0.2 Behandeling 82

Referenties 85

II Geestelijke gezondheidszorg 86

N.G.C.B. van Lin, M.G.H. Laurant, L. Pijnenborg

II.I Depressie 86

II.2 Angststoornissen 89

II.3 Dementie 9I

II.4 Problematisch alcoholgebruik 93

II.5 Chronisch slaapmiddelengebruik 93

II.6 Het gesprek 94

Referenties 95

I2 Bewegingsapparaat 96

H.J. Schers, A.C.M. Romeijnders

I2.I Enkeldistorsie 96

I2.2 Schouderklachten 98

I2.3 Epicondylitis Io०

I2.4 Aspecifieke lage rugpijnklachten IO2

I2.5 Niet-traumatische knieproblemen bij kinderen en adolescenten I03

I2.6 Niet-traumatische knieproblemen bij volwassenen I04

I2.7 Traumatische knieproblemen I05

I2.8 Osteoporose 106

Referenties I08

I3 Gynaecologie en obstetrie IIO

M.S. van Roosmalen, F.S. Boukes

I3.I Vaginaal bloedverlies IIO

I3.2 Subfertiliteit III

I3.3 Zwangerschap en kraamperiode II2

I3.4 Miskraam II3

Referenties II4 
I4 Seksueel overdraagbare aandoeningen II5

M.S. van Roosmalen, J. van Lieshout

I4.I Herpes genitalis II6

I4.2 Fluor vaginalis II7

Referenties II8

I5 Urologische aandoeningen II9

R.J. Wolters, J.S. Starreveld

I5.I Bemoeilijkte mictie bij oudere mannen II9

I5.2 Incontinentie voor urine $\mathrm{I22}$

I5.3 Urineweginfecties I23

I5.4 Urinesteenlijden I24

I5.5 Enuresis nocturna I26

Referenties $\quad$ I27

I6 Huidaandoeningen I29

M.S. van Roosmalen, W.H. Eizenga

I6.I Acne vulgaris I29

I6.2 Dermatomycosen I3O

I6.3 Constitutioneel eczeem I30

I6.4 Ulcus cruris venosum I32

I6.5 Psoriasis I33

I6.6 Bacteriële huidinfecties I34

Referenties $\quad$ I35

I7 Oogaandoeningen 136

T.H. Spies, G.M. van der Weele

I7.I Oogheelkundige diagnostiek, in het bijzonder van refractieafwijkingen ${ }_{13} 6$

I7.2 Het rode oog, infectueuze conjunctivitis en allergische conjunctivitis $\mathrm{I} 37$

I7.3 De uitzondering op de regel I37

Referenties I38

I8 Ooraandoeningen I39

T.H. Spies, A.N. Goudswaard

I8.I Otitis media acuta I39

I8.2 Otitis media met effusie (OME) bij kinderen I4O

I8.3 Otitis externa I4I

I8.4 Slechthorendheid I4I

Referenties I42

Register I43 